\title{
Ant colonies: building complex organizations with minuscule brains and no leaders
}

\author{
Mark W. Moffett ${ }^{1}(1) \cdot$ Simon Garnier $^{2} \cdot$ Kathleen M. Eisenhardt $^{3} \cdot$ Nathan R. Furr $^{4} \cdot$ Massimo Warglien $^{5}$. \\ Costanza Sartoris $^{5} \cdot$ William Ocasio $^{6} \cdot$ Thorbjørn Knudsen $^{7} \cdot$ Lars A. Bach $^{8} \cdot$ Joachim Offenberg $^{9}$
}

Received: 19 November 2020 / Accepted: 6 January 2021

(c) Organizational Design Community 2021

\begin{abstract}
Thus far the articles in the series JOD calls the "Organization Zoo" have employed the notion of a "zoo" metaphorically to describe an array of human institutions. Here we take the term literally to consider the design of the most complex organizations in the living world beside those of humans, a favorite of insect zoos around the world: ant colonies. We consider individuality and group identity in the functioning of ant organizations; advantages of a flat organization without hierarchies or leaders; self-organization; direct and indirect communication; job specialization; labor coordination; and the role of errors in innovation. The likely value and limitations of comparing ant and human organizations are briefly examined.
\end{abstract}

Keywords Ants · Colonies · Individuality $\cdot$ Group identity $\cdot$ Self-organization $\cdot$ Hierarchies $\cdot$ Leaders $\cdot$ Division of labor . Coordination $\cdot$ Stigmergy

\section{Introduction}

Ants live in colonies. These colonies, for certain ant species or for ants in general, have been variously likened to human societies (Moffett 2019), organisms (Hölldobler and Wilson
2011; Moffett 2010), armies (Moffett 2011), agriculturalists (Hölldobler and Wilson 2011), slaveholders (Topoff 1990), and highway builders (Dussutour et al. 2004). Such comparisons have been academically fruitful because, while there's obviously much of interest in comparing similar things (in

\author{
Mark W. Moffett \\ mark@doctorbugs.com \\ Simon Garnier \\ garnier@njit.edu \\ Kathleen M. Eisenhardt \\ kme@stanford.edu \\ Nathan R. Furr \\ nathan.furr@insead.edu \\ Massimo Warglien \\ warglien@unive.it \\ Costanza Sartoris \\ costanza.sartoris@unive.it \\ William Ocasio \\ wocasio@illinois.edu \\ Thorbjørn Knudsen \\ tok@sod.dias.sdu.dk \\ Lars A. Bach \\ lbach@cas.au.dk \\ Joachim Offenberg \\ joaf@bios.au.dk
}

1 Department of Entomology, National Museum of Natural History, Smithsonian Institution, 1000 Constitution Ave NW, Washington, DC 20560, USA

2 Department of Biological Sciences, New Jersey Institute of Technology, 428A Central King Building,, Newark, NJ 07102, USA

3 Management Science and Engineering, Stanford University, 475 Via Ortega, Stanford, CA 94305, USA

4 INSEAD, Boulevard de Constance, 77300 Fontainebleau, France

5 Department of Management, Ca' Foscari University of Venice, Dorsoduro 3246, 30123 Venice, Italy

6 Gies College of Business, University of Illinois, Champaign, IL 61820, USA

7 Department of Marketing and Management, University of Southern Denmark, Campusvej 55, Odense M, Denmark

8 Department of Management, Aarhus University, Fuglesangs Allé 4, 8210 Aarhus V, Denmark

9 Department of Bioscience, Aarhus University, Vejlsøvej 25, 8600 Silkeborg, Denmark 
biology, for example, species sharing a recent common ancestor like chimpanzees and humans), unexpected ideas often arise from finding points of likeness between entities typically thought of as different (Moffett 2020). Furthermore, anthropomorphism, approached critically, has been invaluable since our hunter-gatherer days, being pivotal to the emergence of science while remaining important to how scholars come up with new ideas today (Burghardt 1997; Liebenberg 2012).

In comparisons of ants to people, one pattern of sociality that comes up repeatedly is the potential for complexity to grow as groups increase in size (Garnier et al. 2007). For this reason, army ants and leafcutter ants with colonies in the millions have exceptionally intricate social attributes (e.g., complex division of labor, elaborate supply chains). Generally, a large labor pool can support more complexity than a small one, although this pattern of amplified complexity with size isn't universal-the Argentine ant, whose "supercolonies" can be billions strong, has a simpler social structure befitting a opportunistic lifestyle where the colony labor force is spread out widely across the landscape, sometimes across hundreds of kilometers-a single, socially unified colony that's expanded over time from what had originally been one nest (Moffett 2012).

One productive analogy for ant colonies has been that of the factory within a fortress, where each colony is viewed as a well-protected enterprise for producing the next generation of colonies (Oster and Wilson 1978). Our article gives precedence to larger, and generally more structurally complex, ant colonies, focusing on the factory part of this equation; all the same it should be understood that defending the factory from the competition is a major line item in the time/energy budget of these insects, where the brood is the capital each colony invests in for its growth and reproduction. We bring up the comparisons to human organizations we and our colleagues have emphasized, curious to learn how organizational scholars will view these matters.

\section{Individuality and identity}

Worker ants don't know each other individually. While they can pick out what category a nestmate falls into (e.g., distinguish an egg-laying queen from a soldier or one of the quotidian workers), and consequently respond appropriately to that nestmate, they can't distinguish between individuals of that description. The queen aside, no worker picks favorites. When considering a colony as a society, think of ants as extreme nationalists focused on the success of the whole instead of any particular social connections. Lacking personal social networks, their approach circumvents disagreements of the kind experienced by people, who spend much of their lives finessing relationships and managing disputes; the bulk of human brainpower may have evolved to handle such issues (Dunbar 2010). This isn't to say that ant colonies are without frictionin certain ants, for example, workers can be attacked or killed for laying eggs, a job ordinarily carried out by a queen (Ratnieks et al. 2006). But the surviving ants aren't remembered and picked out as "wrongdoers" over the long term.

In fact, worker ants are devoted to their colonies to a degree that would be the envy of corporate managers. Ants effectively wear a badge of lifelong affiliation to the colony on their sleeves - the members share a unique body scent, an odiferous flag of group unity they acquire on emerging as adult ants. Of course, human jobholders come and go and are not obliged to identify permanently with the firm, which means that human corporations are looser entities than ant colonies. Still, effective organizations like Google or Apple similarly heighten cohesion through a strong group identity, building a corporate culture for example, around dress codes and social attitudes and directing employee efforts toward the same goals and purposes. In fact, it's so easy to think of such a company as a unit that giving a business the legal rights of a person isn't a big step. Hence, the U.S. Supreme Court has repeatedly affirmed the doctrine that the 14th Amendment to the Constitution, which grants people equal protection under the law, applies to corporations as well.

Just because individual recognition is beyond them doesn't mean ants lack individuality. Indeed, they exhibit "personalities," with some workers exerting themselves more than others, for example. So-called key individuals take on most of the labor, and in some situations serve as a catalyst, stimulating others to join in. These "elite" ants may be the first to tackle an urgent job. Remove that single worker and productivity plummets (Robson and Traniello 1999). The same thing happens in any office or factory, the difference being that in ants the high-achievers go unrecognized.

And yet even "lazy" ants may have a value to the colony. Large nests accumulate a pool of inactive workers that can act as a reserve labor force that becomes active in emergencies, as when enemies attack or newly discovered resources need harvesting (Charbonneau et al. 2017).

Variations in the personalities of the ants and the experience of those ants with different tasks can result in colony differences-the rough equivalent of having a corporate culture. For example, colonies become more proficient at moving to a better nest location after their workers have had repeated practice at migrating (Langridge et al. 2004; Dornhaus \& Franks 2008; Cronin 2015).

\section{Absence of hierarchies and leaders}

There's one job that no ant has, an absence that makes their colonies sharply different from most modern human institutions: that of a manager. An ant that happens to be 
in possession of information of immediate value may take charge temporarily, as when a scout worker that's discovered some crumbs lays down a trail of pheromones to guide the throng across your kitchen floor. But this does not rise to the level of what people think of as a leader, someone who handles decisions for the whole group in a substantial and ongoing manner. Even the unsuitably named "queen," who is but an egg-layer, plain and simple, and commands nothing.

Unlike CEOs, who can access information about the global state of their companies and distribute orders and instructions to their employees, an ant's perceptual and communicative ranges are restricted to its immediate surroundings and, in larger colonies in particular, are far smaller than the scale at which the group operates.

Moreover, even if an all-perceiving ant existed, it would still prove unable to make sense of the complexity of the information received and to transform it into actionable orders: with roughly 250,000 neurons, the "brain" of a typical ant is a half million times smaller than that of an average human being. Hence it may be no surprise that an ant is able to carry out just a few kinds of behavioral acts (on average, about twenty: Hölldobler and Wilson 2008). While ants can memorize such information as routes through intricate landscapes (e.g., Wystrach and Beugnon 2009), their cognitive power is too meager to comprehend in detail all the activities in a colony, as would appear to be required to successfully organize its workers. Yet insects with far tinier brains are capable of surprisingly intricate learned behaviors (Polilov et al. 2019), suggesting that the limited behavioral repertoires of ants might represent a functional adaptation to colony life rather than be due entirely to limitations of brain size (for more about ant brains, see Feinerman and Traniello 2016; Godfrey and Gronenberg 2019). As for the ants' inability to grasp the totality of what's happening, the same can be said for the CEO of a major company: Though clearly the CEO operates at a vastly higher plane of reasoning than any nonhuman, he or she nonetheless relies on underlings to distill a sweeping view of the organization.

Instead of evolving to depend on any sort of hierarchy (Bonabeau et al. 1996), ants have taken the organization of their colonies in another direction. Information, as well as the faculty to use it, is distributed across the colony's labor force, which in sum total represents a kind of collective mind, or swarm intelligence (Camazine et al. 2001; Couzin 2009; Garnier et al. 2007). This absence of centralized control enables ants to respond immediately to local problems and allows for continuity in work output even when individuals fail to carry out a job or die. Such features also make it harder for competitors to bring down the colony. In contrast, hostile actors can bring human institutions to a standstill by targeting a key building, central data repository, or leader.

\section{Flat organizations}

The ant workforce, then, is self-directed, adjusting to local conditions without the oversight of foremen or any hierarchy of control. Early human hunter-gatherer societies, spread out in small, mobile groups, operated in the same way. But while our kind added hierarchies and leaders to their societies as they expanded (and to the institutions that flourished within them), ants in colonies small or large always manage to do without.

In business terms, a colony has the flat organizational structure adopted by some small businesses that function without seniority or managers. Some big corporations remain relatively flat but still require some hierarchical oversight; authority figures have been indispensable when human groups grow large, to mitigate conflicts and coordinate activities. Still, companies from Hewlett-Packard to IKEA try to dispense with middle management, which enhances their cost-effectiveness and organizational responsiveness to rapid economic shifts (Davidow and Malone 1992). Employees in such organizations tend to be more involved in making decisions than employees in hierarchical organizations; nevertheless, even in completely flat companies people are likely to turn to experienced seniors for advice and information or choose familiar colleagues when a job unfamiliar to them needs to be done (Morgan 2014). Ants, which fail to know each other as individuals and thus can't learn which workmates are reliable, don't develop such preferences.

\section{Self-organization}

In the absence of leadership and decisional hierarchy, ant colonies have evolved an extraordinary ability to selforganize. Self-organization, simply put, is the bottom-up creation of a large-scale structured conglomerate arising exclusively from interactions between individuals, without following a pre-established plan or receiving top-down guidance (Camazine et al. 2001).

In the seed-harvester ants of the southwestern United States, workers perceive how many compatriots are devoted to different tasks by the scent each passerby has picked up from its environment-one of several instances where ants accumulate evidence before making a decision. The workers then adjust their efforts accordingly, shifting, say, from building the nest to foraging should foragers be in short supply. (Not that all reassignments are possible: once ants turn to foraging, they never go back to nest maintenance, for example: Gordon 2010.) Assessments by individual ants of colony labor demands will 
vary, but when all those choices are taken in aggregate, the collective behaves sensibly. This "in search of work" method enables a colony to effectively redistribute labor in response to ever-changing conditions without the need for supervision. One result of the greater information flow in big colonies is they are more stable (homeostatic) over the long term than small ones (e.g., Wenzel and Pickering 1991), enabling them to bounce back from environmental or economic perturbations.

The basic mechanism is simple, as is required given the limited perception/action/cognition of the ants (Seeley 2002), but the consequences at the scale of the colony can be orders of magnitude more complex than any single ant could achieve on its own (Garnier et al. 2007; Moussaid et al. 2009). Locally, an ant and its immediate neighbors influence each other's actions constantly. This creates positive or negative feedback loops that can increase or decrease the propensity of each ant to perform certain actions next. Since each ant and its neighbors are connected to other ants and their respective neighbors, these local changes in behavior can propagate quickly throughout the entire colony like a giant game of dominos.

And forget about the butterfly effect: these behavioral cascades in ant colonies have far more interesting outcomes. For instance, certain kinds of army ant move forward in fanshaped swarm raids many meters wide that contain hundreds of thousands of workers in an engagement that can truly be described as "self-organized." None of the ants can conceive of the raid in its entirety or know where it's going. Raids emerge from the separate decisions of the incompletely informed masses, with each worker contributing so infinitesimally as to be essentially irrelevant to the outcome (Fewell 2003). Raiding workers coming upon prey release a pheromone to attract further ants, which help them take down that prey; the newly recruited workers, in turn, release more pheromone once they have assessed the quality of the prey, and so on and so forth; the biggest mass of ants is, therefore, likely to pour into whatever sector of the raid builds up the highest concentrations of the pheromone, causing the raid as a whole to expand fastest and move in the direction where the ants in it have the most success (e.g., Moffett 1988). A human version of such behavior likely influences the effectiveness of, say, sales teams, such that "this kind of collective intelligence is a property of the group itself, not just the individuals in it" (Woolley et al. 2010, p 687).

In certain other ant species, the collective decision of the colony to relocate to a new nest transpires by a mechanism akin to "quorum sensing," in essence making the choice through voter turnout (Franks et al. 2009). This occurs when the colony's nest is no longer adequate-a risky situation that requires speedily pinpointing a suitable home. Prior to a relocation, the workers explore to find a substitute destination while checking out the sites discovered by the other scouts. When the ants detect that enough nestmates have gathered at one of these particular options, a behavioral switch is triggered in their tiny brains: they stop their exploration and start laying down a pheromone trail to that piece of real estate, attracting even more workers that in turn stop exploring and start laying even more pheromone. Very soon, the whole colony migrates there, giving the impression that a well-concerted decision was made (Visscher 2007).

\section{Direct and indirect communication}

Not unlike humans, ants organize collective activities through different modes of communication. It is, for instance, common to see ants crossing each other's path stop for a few seconds and frantically tap their antennae, the functional equivalent of our nose, over the head of their partner. In doing so, they directly transfer information about their identity, their activity, the places they've visited, and so on, through subtle odorant cues (Hölldobler and Wilson 2008).

Another form of direct communication between ants is the alarm drumming produced by certain species of carpenter ants (Hölldobler 1999). On sensing a danger, they smack their heads and abdomens against the walls of the chambers and galleries they've carved out in the rotten wood or stumps where they reside. The vibrations that this intense drumming creates can be perceived by nestmates twenty or more centimeters away, alerting them of the danger to come.

Direct communication has the advantage of transferring information to other individuals immediately. This allows the group to react quickly to changes in the environment, such as the presence of an imminent danger. However, direct communication is often limited to the individuals present at the moment the signal is emitted, and the information it carries can propagate only in densely packed groups (as occurs, for instance, of the dazzling ballets of flocking birds and schooling fish). Ants spread out over territories, where they have to operate in an asynchronous fashion, and colonies therefore require additional means of communication better adapted to these circumstances.

This is where indirect communication through stigmergic traces comes into play (Theraulaz and Bonabeau 1999). Stigmergy, a concept first developed for social insects (Grassé 1959), describes how the products of past efforts can channel the work of other individuals, sometimes much later, as occurs when people add to the entries on Wikipedia (Elliott 2006) or program software using GitHub (Burton et al. 2017). In ants this can give the impression that a colony is following a carefully wrought plan. Imagine one bricklayer after another walking by a half-laid wall, each one adding a few bricks in appropriate places before moving on-ants construct walls much this way. Stigmergy explains how a colony comes to prefer the most profitable (richer or closer) 
resources without any ant comparing the different options: more of the ants visiting the richest site are induced to reinforce the trail leading to that food by adding their pheromones, thereby accelerating the recruitment of further ants from the nest to follow the trail out and collect that food (a positive feedback loop); additionally, the workers travel back and forth in the least time along the shortest trails to their meals, speeding up the harvesting of resources that are conveniently near their home (Detrain and Deneubourg 2008).

\section{Mistakes and innovation}

Ants in a large colony operate in "series-parallel," the many working at once in response to the variety of opportunities or difficulties as they arise-a striking advantage over the efforts of an individual acting alone, which can typically complete just one task at a time (Oster and Wilson 1978). Not only can they quickly complete a high volume of repetitive tasks, but the fact that one particular ant doesn't finish some duty like fabricating a wall simply means that another will likely take over. Even if a problem occurs, the next ant that comes along will likely correct it. It's common to see the occasional ant carrying food in the wrong way or depositing a bit of building material at a spot that makes no sense. Such blunders could be lethal for a solitary creature that has but one chance to do a job right; the same may be true for a small ant colony. In them, the few workers carry out every move with far more care than those occupying a huge nest, where the sheer number of performers ensures success.

The fact is that, with sufficient redundancy, sloppiness can lead to useful novelty and innovation, as when an ant on a crowded trail overshoots the targeted food and, in its wandering, lucks upon a different meal. Errors tend to be most common when the colony benefits most from them. Ants are more likely to stray from a pheromone trail when it's so new that its path is still weakly defined. At this early stage, ants failing to orient along the trail have a good chance of meandering across other food sources that may be present in the same general area (Detrain and Deneubourg 2008). By the time this exploratory phase is done, the original trail has become well demarcated, such that most of the ants on it successfully reach its end and concentrate on the food there.

Particularly for species that exploit short-lived resources, though, it isn't uncommon to observe a significant number of workers straying away even from well-established trails to wander around aimlessly — with positive yields (Deneubourg et al. 1983). Thus, it is conceivable that that error rate is not a bug of the system but one of its best evolved features. When supply is not a long-term guarantee, exploring constantly (in humans, by setting up an R\&D department), albeit costly and seemingly pointless in the short term, may prove a winning strategy when the wind changes.
Arguably, then, ants have experienced little evolutionary pressure to become more individually smarter. Human innovations have often come to light through pure accident as well (Firestein 2016), although to our knowledge no corporate strategy is as reliant on outright mistakes as are ants.

\section{Specialization}

Colony members are differentiated into labor specialists. The most universal of these is the split between the reproductive individual or individuals, or queens, and the workers, a distinction with no parallel in humans, so we won't consider it further except to say that protecting its investment in the output of future generations requires the colony to keep the reproductives healthy and safe.

Of greater interest here is that the workers can be further specialized in their labor roles by age and anatomy, depending on the species. Adult ants generally start off where they are born, tending the larvae in the nests, but as they age and explore farther afield, they turn to foraging, infrastructure assembly, and other work. But just as a person trained as a surgeon rather than a chef can still cook at home, specialization in ants doesn't mean an individual is incapable of doing other jobs. Hence, take away the young nurses and the older "foragers" can revert to nurse duty (e.g., Calabi and Traniello 1989). In such cases, the different worker "castes" may have a higher response threshold-probability of responding when a job presents itself-for doing work for which they are a poor fit. Despite this flexibility, workers show a smaller repertory of behavior than do solitary species for which each individual must carry out every single task by itself.

Labor specialization by physical appearance is a remarkable characteristic of some species. In the same way we may guess that a person wearing a hard hat is a construction worker, it's possible to infer that when a colony has a range of worker sizes and the larger ants have powerful jaws, the bemouths are likely to serve in defense (i.e., belong to the soldier caste, although in some species they fulfill other duties, for example using those jaws to chop open seeds for their weaker compatriots to eat). This physical polymorphism is expressed by workers of different sizes having differently proportioned body parts to suit their usual employment. Such differences aren't a matter of age. Ants stay the same fixed size throughout their adult lives. A colony therefore has to produce the right number of workers of each kind to meet its labor needs. While corporations adjust their personnel to suit current requirements through hirings and layoffs, at least some ants can alter the workforce by favoring the raising of workers of the most needed caste (e.g., produce more soldiers during periods of conflict with outsiders: Passera et al. 1996; McGlynn and Owen 2002). 
Labor specialization can go hand in hand with the emergence of other aspects of organizational complexity, notably in infrastructure, as colonies expand. Tiny colonies may barely need a home base, whereas the largest leafcutter ant nest can extend ten or more meters wide and down seven meters to the water table, with a labyrinth of corridors that would be kilometers long if scaled to human dimensions, connecting hundreds of chambers, some for rearing the domesticated fungus that these ants eat, others for trash and diseased food that specialized sanitation squads bury deep underground in much the way humans get rid of nuclear waste. The belowground architecture is arranged to form an air-conditioning system that keeps the collective cool. A highway system extending as far as seventy meters from the nest permits the available labor pool to move rapidly to resources or sites under threat from competitors. With millions of years of experience in such matters, compared to a few centuries for humans, these colonies may invest more heavily in infrastructure and public health than most human organizations (Moffett 2010; Hölldobler and Wilson 2011).

\section{Coordinated labor}

Sometimes a job has to be coordinated among work specialists. This can amount to teamwork in which the job is partitioned among several ants acting simultaneously (Anderson and Franks 2001). The ants may belong to different labor specializations: for example, when certain army ants carry food, a hefty worker generally does the powerlifting and steering while one or more agile little ones keep the item's trailing end from dragging. In other situations, every worker involved is able to do any of the tasks and will switch between the duties as needed: When Asian marauder ants need to haul a bulky item, the workers surround it, each walking in a suitable manner to accommodate the direction of transport, with those at the forward margin heading backwards and so on.

Multiple ants can also collaborate on a job by executing a series of tasks sequentially. Marauder ants collect seeds from grass plants. The small workers (called minors) are first to climb the slim stalks but gnaw the attached seeds ineffectually. Productivity skyrockets when a larger ant (called a media) arrives: the ants set up a little assembly line, in which the media extracts one seed after another and then seems to hand it to a minor to haul away. What is really happening is that the minor, which is too weak to pull a seed free on its own, snatches the seed from the media before the larger ant can depart with it. The media dutifully plucks the next seed, which the next minor grabs. With minors so numerous, a media seldom has an opportunity to exit with its find.

Leafcutter ants operate using a more complex and highly regulated assembly line to turn green leafy material into a mulch on which the colonies grow their domesticated food, a fungus species found only with these ants. A leafcutter factory might have been the envy of Henry Ford: different workers collect, transport, and mince foliage, apply it to their subterranean gardens, and eject its decayed remnants in an orchestrated flow of material from environment to nest and back out again. Many steps are managed by ants in a narrow range of sizes. Midsized workers cut the foliage from a plant, carry it into the nest, and drop it onto the garden surface, where, as the production line unfolds, ever smaller ants accomplish more delicate tasks. Workers with heads $1.6 \mathrm{~mm}$ wide shred the greens into scraps. Slightly smaller ants further masticate the chunks, now discolored from abuse, into a moist pulp. Still smaller ants, using their forelegs, implant the pulp into the garden. Tiny ants with heads a millimeter wide lick the pulp and seed it with tufts of fungus from established parts of the garden, like horticulturists using vine cuttings to plant a new crop of grapes. The smallest workers of all reach into the garden's recesses to remove weedy species and contaminants that include bacteria, yeasts, and spores. Many of these steps would be familiar to farmers; indeed, the ants even apply their version of a pesticide to the food crop: a bacterium that kills weedy parasites that can destroy the gardens (Hölldobler and Wilson 2011).

The flow of food and other goods in a colony is regulated by what's available and what's needed, a supply-anddemand market strategy (Cassill 2003). This is best observed in the workers of the red imported fire ant, which monitor the nutritional needs of the other adult ants (which require carbs for quick energy) and of the brood (which is hungry for protein necessary for growth) and change their actions as necessary (Sorensen et al. 1985; Dussutour and Simpson 2009). Foragers that converge on the nest laden with a variety of foods hawk their merchandise by regurgitating samples into the mouths of "buyers" in the nest chambers who in turn roam through the nest to distribute the meals to the larvae and queen. If the buyers find their "customers" have become sated on meat, they peruse the marketplace for other commodities, until they find, maybe, a seller offering nectar. When the market becomes glutted and sellers can no longer peddle their wares, both buyers and sellers wander away to engage in other jobs, or take the afternoon off.

\section{Lessons for humans}

Ants are among the most ubiquitous and successful life forms on earth, but why? This dominance has more to do with the scale and efficiency of their operations than with social novelty, innovation, or intelligence given how simple and limited the behavior of individual ants tends to be (Oster and Wilson 1978). A colony is a model of bottomup organization: highly decentralized coordination between 
individuals with limited behavioral repertoires generates complex functions and provides robustness to failure; this model even allows failures to be exploited for innovation. That combination has inspired engineers to create, for instance, successful ant-derived optimization algorithms for routing and scheduling, and robotic controllers for automated warehouse management (e.g., Demaitre 2019).

Can the same principles therefore be widely applied to human organizations? Yes...in theory. Evolution has refined the decentralized coordination of ant colonies over millions of years to drastically reduce error propagation and runaway failure, the worst enemies of any fully distributed system. In a human-centric context, therefore, control mechanisms would have to be carefully engineered to guide the self-organization of people toward the specific objectives of institutions. While parallels of ant colonies to human organizations are manifold, this field of study remains largely unexplored and inevitably vulnerable to ethically questionable practices in crowd 'management.'

Until we learn to self-organize better, we can remain in awe of what great collective feats such tiny brains are capable of. King Solomon advised us to "Go to the ant, thou sluggard, consider her ways and be wise." We may indeed become wiser by considering the ant's ways, such as the value of investing heavily in infrastructure and sanitation (Moffett 2019). As more research is done in this area, it will be fascinating to see what insights into human organizations will follow.

\section{Non-hierarchical organizing: lessons from the collective intelligence of ant colonies}

A fundamental question within the organization and strategy fields asks: Why do organizations exist? The answers largely draw on explanations like coordinated action (Chandler 1977; Galbraith 1973), transaction costs (Coase 1937; Williamson 1981), and resource ownership (Barney 1986; Penrose 1959). The idea of control, often through hierarchy, frequently accompanies these explanations. Yet as communication costs decline, markets trend towards turbulence, and global challenges from health to climate change rise, the value of hierarchy is increasingly questioned (Altman et al. 2015; Baldwin and von Hippel 2011).

In the search for alternatives to hierarchy, entrepreneurs and executives are engaging in a grand collective experiment with non-hierarchical organizing forms like holocracy (e.g., Zappos), agile (e.g., Spotify and ING), market-based (e.g., Disco), and community (e.g., Linux, Wikipedia). Although passionate advocates often tout their favored form as the cure for the disease of hierarchy, there is too little known about these and other non-hierarchical forms (e.g., what works, why, how, and under what circumstances). Indeed, the foundational principles for designing effective non-hierarchical organizations have yet to crystallize.

A way forward is to look at non-hierarchical systems in other domains. Entomologists Moffett and Garnier provide a rich description of the flat, leaderless, cognitively challenged yet successful organization structure of ant colonies. Ant colonies contain valuable clues for designing non-hierarchical organizations of humans. Most significant, ant colonies may inspire a provocative answer to the fundamental question of why organizations (or firms) exist at all: collective intelligence.

\section{Learning from evolution}

As beneficiaries of 150 million years of evolutionary refinement, ant colonies sharpen what non-hierarchical forms can do well. For one, ants appear to operate by "simple rules" or heuristics that guide and simplify action. For example, ants lay pheromone trails when they encounter crumbs, find a particular new home when enough nestmates gather there, and coordinate lifting heavy food bits between big and small ants. In fact, locusts, dragonflies, honeybees and other insects also appear to follow heuristics (Seeley 2010). These rules work because they simplify decision making to its essentials without necessarily sacrificing much accuracy (Jung et al. 2017). They're easy to remember and followperfect for small brains and busy, stressed humans. Simple rules also work because they give guidance, but allow flexible action (Bingham et al. 2007; Davis et al. 2009). So ants can find new food sources, but not stray too far. Similarly, organizations relying on simple rules from the Jesuits to Pixar can adapt to unexpected circumstances, but maintain a coherent mission (Sull and Eisenhardt 2015). Finally, since simple rules are uncomplicated to convey and enforce, they are useful for coordinating large groups-whether of ants, Wikipedians, or Zipcar renters. As substitutes for hierarchy, the simple rules of ants seem central to making their nonhierarchical organizing form work.

Second, while we were extremely surprised that ants can coordinate at all (and that they have personalities and cultures!), their coordination is mostly impressive by human standards because of its scale. Indeed, ant colonies seem to be tackling primarily simple (nearly decomposable) tasks for which modular problem solving at scale is particularly effective. That is, these problems can be very large (e.g., building a mega-nest seven meters into the ground), but are not complicated by extensive interdependencies or for that matter, by much true novelty. These observations suggest that leaderless forms will fit well with nearly decomposable tasks like software projects where design rules provide sufficient coordination (Baldwin and von Hippel 2011). Examples include GitHub and Linux. The non-hierarchical form 
also likely works well for product platforms like iTunes, marketplaces like Airbnb, and user communities of hobbyist enthusiasts like the Adult Fans of Lego (Lakhani et al. 2013). Here individuals choose to join (or not), and typically don't want lots of rules and hierarchy when they do. Like ant colonies, these kinds of organizations benefit from size and diversity-i.e., more and more heterogeneous apps, places to stay, and Lego enthusiasts. Like ant colonies, these kinds of organizations often become more specialized and capable of complex behaviors (O'Mahony and Ferraro 2007). That said, increasing complexity is not always an advantage-a point sharpened by the more likely homeostasis of large, mature ant colonies, and stagnation of large, mature nonhierarchical organizations of humans like Wikipedia (Halfaker et al. 2013).

Third, ant colonies are robust. An ant can wander off and find something new. This exploration may turn out well. But if not, another ant can quickly come to take its place. So ant colonies are robust organizations that exploit extreme modularity. This path to robustness works well for Army special forces and guerilla fighters as well as for large and long-lived organizations like Johnson \& Johnson and very flat ones like the successful steel-producer. Nucor. Like Isis, such organizations are hard to stamp out. Of course, modular organization is not an entirely new idea, but the degree of modularity used by ants does challenge our thoughts on the limits of organization. Moreover, extreme modularity isn't just for ant colonies. When Jeff Bezos sent an email to every employee instructing that all Amazon activities would occur via application program interfaces (no exceptions or be fired), he signaled a radical form of organizational modularity that has helped the company to scale in ways that seem reminiscent of an ant colony.

\section{Limits of evolution}

While much can be learned from the organization of ant colonies, there are important differences that sharpen what ant colonies and broadly, non-hierarchical forms cannot do well. First, although ants encode simple learning in pheromones, they lack the sophisticated learning processes and problem solving approaches that humans can leverage. For example, ant colonies mostly use trial and error learning. Yet they lack more sophisticated processes like systematic parallel experimentation, rapid serial experimentation, and passive learning that require timing and coordination to reduce targeted uncertainties and accelerate knowledge acquisition (McDonald and Eisenhardt 2020). Likewise, ant colonies engage in modular problem solving, but not hybrid problem solving approaches that fit novel complex problems (Baumann and Siggelkow 2013; Ott and Eisenhardt 2020). Bremner and Eisenhardt (2020) illustrate. They compare innovation at two civilian drone makers: 3DR which organized its innovation around a user community while DJI organized around a firm-based hierarchical form. The community initially did well for unexpected innovation where broad exploration and lowcost randomness paid off in the emergent market. But it lagged when the innovations became complex and novel (i.e., uncertain) like integrating many cutting-edge technologies and components into a polished consumer drone for a growth market.

Second, ant colonies may occasionally move their nests, but they only slowly update their rules and never transform into something else. By contrast, human organizations do both. For example, Bingham and Eisenhardt (2011) describe how some entrepreneurs learn different types of "simple rules" heuristics and then make them better over time-i.e., more abstract and strategic. Further, some leaders transform their organizations. Take Netflix leaders who went from mailing DVDs to completely upending the rules of television by producing and streaming shows like House of Cards (Sull and Eisenhardt 2015).

\section{A new answer for the question of "Why Do Organizations Exist?"}

Perhaps the most intriguing insight from ant colonies for organization and strategy scholars is that they facilitate the emergence of collective intelligence from the self-directed actions of many. Further, if benefits emerge from the selfdirection of ants, then how much more profound are the benefits of self-direction for humans with our deeper individuality and creativity? This is a motivating principle for Valve, a gaming software firm which operates without managers and job titles (Puranam and Håkonsson 2015). The view inside Valve is that if a company "spent the last decade going out of its way to recruit the most intelligent, innovative, talented people on Earth; telling them to sit at a desk and do what they're told obliterates 99 percent of their value" (Furr and Dyer 2014, p.53).

Thus, perhaps the most valuable feature of non-hierarchical experiments like agile, user communities, marketplaces and holocracy is collective intelligence. What if organizations (or firms) exist to tap into the collective intelligence of many self-directed actors, rather than to coordinate action, specify contracts or shepherd resources? This provides a provocative answer to the classic question: Why do organizations exist? By framing the answer as collective intelligence, we can think differently about the purpose of the organization-as potentially activating something greater than, different from, and potentially more valuable than the sum of its parts. Activating "collective intelligence" may then be the next frontier of organizations, one that draws on the long evolutionary past of the humble ant. 


\section{Stigmergy and the coordination of emergent division of labor}

Moffett and Garnier offer a rich bundle of provocative organizing principles, drawn from their work on ant colonies. Our pick selects two of them: on one hand, the spontaneous division of labor, on the other stigmergy - and the related behavioral cascades. These principles are tightly connected, and we believe they offer a coherent perspective on social self-organization phenomena, as well as a relevant ground for stimulating comparisons that may go beyond the consolations of metaphors. We actually believe that these principles are together at work in specific, relevant human organizing processes, and hold potential for describing and possibly modeling them.

\section{Spontaneous division of labor}

Social insects do not divide labor according to plans or commands. They do it in a distributed way, and the actual division of labor results from a host of individual decisions. From an organization theory point of view, it is useful to distinguish two aspects of division of labor: task division (related to the task content) and task assignment (Puranam 2018). There are predefined macro-roles that limit the access to specific tasks to individual social insects, often based on physical attributes. Still there is room for a wide range of specific task contents that social insects can bundle and perform, and their details are left to the situation they face. What's more, many insect societies have "unspecialized" members that can be addressed to covering very different roles whenever such roles are vacant. It is in task assignment, however, that insect societies seem to display the strongest properties of self-organization. Which specific task to perform is to a large extent an individual choice. Single colony members are continuously "in search of work", although there are rules of collective aggregation and coordination at work. Incidentally, insect societies provides the most obvious evidence that division of labor is not driven by trade and can be rather independent from it, and its origins have to be found in reciprocity, not in market exchange (see the compelling remarks of Smith 1998).

\section{Stigmergy}

Grassé (1959) first introduced the concept of stigmergy to explain the paradox of coordination in termites' nests. How could colonies of individuals acting with no apparent concern for others' actions achieve such a level of coordination and complexity in the nest architecture? Grassé's answer was that the construction itself is the stimulus triggering specific responses from workers, as it provides all the information needed to coordinate the activities. For Grassé, stigmergic coordination critically depended on the "significance" of the work realized as a stimulus for further activity, and on critical mass effects triggering behavioral cascades ensuring that single constructions are completed even in the absence of stable teams. In recent years, a small group of researchers (Elliott 2006; Heylighen 2007; Rezgui and Crowston 2018) has claimed that stigmergy applies also to human organizations. It has been suggested that stigmergy is "a third alternative to the traditional dichotomy of explicit and implicit coordination" (Rezgui and Crowston 2018, p. 1), even if motsly neglected by organization students. Interestingly, examples of stigmergic coordination have been sought in highly symbolic, abstract activities such as coding in Open Source communities or modifying wiki pages (Elliott 2006). While there is an undeniable aspect of materiality even in such highly symbolic practices (Faraj and Bijan 2012), they presuppose a high level of standardization of the material being transformed, of rules of access to it, and of skills. In these cases, stigmergy acts on the top of a large amount of planning and standardization. Nevertheless, stigmergy can be found also in organizing activities where the materiality of stimuli is much higher and standardization of materials is very low.

Indeed, little attention has been given to behavioral cascades triggered by stigmergic coordination-a component that was crucial in Grassé's original description of insect colony coordination. As we shall see, we will argue this is a crucial aspect of stigmergic coordination on particular forms of human organizing as well.

\section{Organizing like ant colonies?}

Taken together, spontaneous division of labor and stigmergic coordination offer a coherent concept of distributed organizing of activities (Theraulaz and Bonabeau 1999). But are there species in the human organizations' zoo whose working can be explained or even modeled by such principles? It is not easy to find such examples in the domain of formal organizations, although some ideas have increasingly percolated into organizational practice. Principles of spontaneous task self-selection are found in "holacracies" (Robertson 2007). "Ant optimization" algorithms can be found as a tool for managing operations and logistics (Yu et al. 2009). However, they often appear as single elements within more traditional structures rather than as a coherent organizing system. As discussed above, open source communities and platform business models seem to translate some principles of stigmergy, but operating over symbolic systems with strongly shared grammars, and only on highly standardized materials and processes. 
A more radical resemblance can be found in temporary, spontaneous organizations such as those developed in response to emergencies and catastrophes, such as earthquakes, floods or tzunami. For example, some observers of the "Occupy Sandy" organization (created during the post-hurricane Sandy emergency in the areas of New York and New Jersey in 2012) suggest that principles of stigmergic coordination have widely characterized such disaster response effort (Marsden 2015). Moving closer in time, we report here some additional evidence from our ongoing study of the spontaneous relief response to the catastrophic high tide that hit the city of Venice on the night of Tuesday 12th November 2019. On that night (and the following days) the salty lagoon's waters flooded the whole city causing enormous damages. Since the morning after, a group of young citizens decided to start helping affected people by taking care of damaged buildings and goods in a selforganized process. Following initially sparse calls on social networks, a growing number of people both from Venice and the surroundings mobilized, armed of boots, gloves and plastic bags to provide help: in the next days there were more than two thousands "Water's Angels" helping citizens in need.

Looking at the organizing logic of the events, the catastrophe immediately activated spontaneous community response. As the response became visible, people in need started signaling problems near-by: they moved from selfhelp to requesting help. This generated a flow of observable needs both by explicit signaling and by direct material observation. These observable needs became immediately the focal points of self-organizing activities, triggering swarming behaviors and stigmergic response. Once mobilized, relief volunteers arriving in the place tended to aggregate with others (often found along the way or at the rail station) in order to find the location where their help was most needed. These swarming dynamics worked both in upscaling, aggregating more people where help was needed the most, and in downscaling, splitting groups when overcrowding was perceived or when other opportunities were observed along the way. The spatial dimension was the first level of division of labor since it was based on the directional communication received, the material distance of the problem, and the group size and density of the relief group. Once focal areas were reached further levels of division of labor occurred both in macro and micro tasks. At the macro level there was a spontaneous allocation of efforts between different target bundles of activities (e.g. cleaning the floor of a church from salt or drying the manuscripts of a neighboring archive). At the lowest level the definition of micro-tasks and the assignment of the individuals to such tasks was a highly spontaneous activity whose coordination was driven by clear stigmergic dynamics (e.g. sweeping a church's floor from water if brooms were available, or filling buckets of clean water and move benches if they were not available). This is where human action patterns resembled ants' ones the most. Individuals constantly shifted from tasks and tools continuing the work started by others, shifting to new tasks as they got tired or bored, exchanging tools at disposal or matching their strength and abilities to the available tasks (e.g. to raise heavy church wood benches required physical strength, while the precision needed to put paper towels in between the pages of a wet manuscript to dry it out required manual abilities). The combination of volunteers' cascading activation, spontaneous division of labor and stigmergic coordination were very effective and quickly relieved some of the most urgent problems in town, but at the cost of a high inefficiency due to the spontaneous, improvised design of the tasks' division and to the redundancy in tasks' assignment. Since the second day, this led to the gradual structuring of response activities trough the emergence of virtual and physical hubs collecting needs and distributing people among them. In this phase a crucial role was played by social media platforms such as Facebook or Telegram, that local associations like Venice Calls used to coarsely match needs and responses. The whole response system moved from completely decentralized and spontaneous to polycentric, from stigmergy and swarming to explicit signaling and (coarse grained) task routing. A second feature of relief response's subsequent structuring to high tide has been the coupling of these spontaneous organizations with more formal ones, such as the local garbage collection corporation that helped in providing boats in places of need for carrying collected trash to the dumping. This suggests that these almost pure self-organizing processes may be mainly transitory. In the immediate aftermath of catastrophic events existing rules and systems are disrupted, and a quick scaling up of activities is essential to promptly intervene, while the inefficiency of redundancy can be easily tolerated. As immediate emergency is left behind, efficiency is sought: a hub system emerges, and the coupling with superior resources of formal organizations takes place. Thus, while strong principles of self-organization such as those observed in insect colonies may not be stable in human organizations, they may shed considerable light on the emergence of organizations.

\section{Enlarging the picture (and blurring boundaries)}

While the compelling similarities offered by Moffett and Garnier can illuminate human organizing principles, we think that their paper should also stimulate more radical reflections. We submit that maybe it is time to move from comparing human and non-human organizations, to enlarging our view on how human organizing processes include both human and non-humans agents. Studies of laboratory life have already shown how labs are the stage of complex strategic interactions between scientists and the 
living entities they study (Latour and Woolgar 1979). Moving toward a more systemic perspective, Atran and Medin (2008) have convincingly shown how in a same geographic area of Guatemala native Mayan population attributing agency to natural resources are more able to preserve their commons than other population living in the same environment. This population better organizes its resources since it envisions a commons' game in which non-humans agents are conceived as players, compared to the other populations in which non-humans agents are just payoffs. Historically, our model of economic thinking and organizing is grounded on the conception of natural resources as passive entities or as mere payoffs in a game played by humans only. Nevertheless, many human organizations are deeply entangled with natural entities (and not only resources), which play important roles in the reproduction of organizational processes themselves. Is time ripe for re-thinking organizing as more than a human-only process? We believe this is a serious and urgent challenge facing organization theorists.

\section{On ant colonies and human organizations}

Ants of different species, with minimal brains, no culture, and no hierarchical leadership rely on geneticallyprogrammed systems of information processing and communication to build large scale cooperative societies. Ant societies number in the thousands, millions, and for some specific species, even billions of members. Moffett and Garnier in a fascinating article in the JOD series of the "Organization Zoo," examine the organizing characteristics of not of another human organizational form, like other articles in the series, but of ants, a taxonomic family of insects that can produce, according to Moffett and Garnier, more large and complex forms of social organizations than any other living species besides humans. Significantly larger than those of our close primate relatives, like bonobos and chimpanzees. The article emphasizes the role of self-organization, with speculations hinting at, if not directly claiming, that us humans should limit, if not abandon, hierarchical organizing and rely more on self-organizing strategies as do ants.

I found the normative implications for human organizations not particularly credible, and to a great extent, misinformed. (I will say a bit more about self-organization later in my commentary). Yet there is a lot that we can glean from Moffett and Garnier's article to further our understanding of the microfoundations of complex human organizations and their design. But to do so I believe it's important that we spend more time comparing not only the similarities but also the differences between ants and humans and their respective organizations.

First, the analogy between ant colonies and human complex organizations, as we have come to understand the term organizations (e.f., firms, schools, hospitals, government bureaucracies, charities, etc.) is overstated, if not misplaced. Ant colonies are organized more like human polities, a sort of leaderless communist society and state, where individual differences are not acknowledged and genetics, rather than culture or authority rule. The ant society cooperates in both collective "factories" and "supply chains" of food production, highlighted in the article, as well as common defense and war against other ant societies (acknowledged but less emphasized). Moffett and Garnier recognize the "nationalistic" nature of ant allegiances, but seem to equate them with identification with a corporate culture like that of Google or Apple. But unlike ants, humans have multiple social identifications, and do not have total complete allegiance to an organization or engage in ultimate self-sacrifice as ants do to their societies.

Unlike in human organizations, there are no individual, specialized organizations within ant colonies, with markets or trade between them or inter-organizational relations (although ant colonies do appear to get captured and assimilated). "Demand and supply" do regulate food production and consumption within ant colonies, but as described in the article, this appears to be equilibrium the demand and supply of food among ants and is driven by generalized altruism within ant colonies, quite different than markets internal or external to human organizations.

Moffett and Garnier do make evident a key to understanding ant colonies and their differences with human organizations and polities. Ants, unlike humans, do not recognize each other individually — and this difference is key. While individual differences in ant productivity and work specialization do exist, there is not recognition by other ants for those variations. There a no apparent rewards for performance (more food for expenditure of energy perhaps, but more out of functional necessity than an incentive of any sort). This leads to the interesting observation that when more productive ants are removed, productivity in the ant colony plummets. Yet higher performers are not rewarded nor are laggards punished. And given the lack of individual recognition, although ants are social insects there is no sociality as we understand it in humans (or other animals for that matter): no friendships, inter-individual relations, no need for trust. As the article indicates ant communication is thereby reserved for work (including war and defense). Given that human do recognize other's individuality (and their own), incentives, status differences, and social relationships are key elements in understanding microfoundations of human organizations and their social hierarchies.

Despite these and other differences, ant societies and human organizations do share important commonalitiesthey are both distributed social systems for controlling and coordinating collective action. They both rely on distributed information processing and division of labor. And perhaps 
even more notable, ant colonies and human organizations both rely on direct and indirect communication to achieve collective action. Ant colonies and human organizations are both cooperative systems although within human organizations cooperation is always combined with competition, whether for status, economic rewards, social affiliations, or control. Ant colonies and human organizations both exhibit collective intelligence in ways that exceed the individual knowledge and intelligence.

Of all the similar functions between ant colonies and human organizations, a particularly instructive one is the importance of direct and indirect communication for collective information processing and coordination. Theories of organizational design (e.g., Tushman and Nadler 1978) highlight the centrality of information processing but typically pay less attention to communication, particularly indirect communication. In ant colonies direct communication occurs through various senses including sight and sound but more notably smell. And smell, through secreted pheromones, is critical for indirect communication and for the coordination of control of collective action beyond the dyad. Moffett and Garnier examine the importance of stigmeric traces for indirect communication and coordination. As ants traverse through the environment they deposit pheromones which create traces that other ants follow, both or pathways as well as smells. Stigmeric communication then creates a mechanism for coordination across large number of ants following the same traces of pheromones as they accumulate across ant trails, allowing for self-organizing systems of coordination-or self-organizing without hierarchical control.

Communication is also critical for coordination in complex human organizations (Putnam and Nicotera 2009). But while human also rely on non-verbal forms of communication like pointing and gesturing, it is language which is the truly distinctive characteristic of humans that facilitates cooperation and collective action (Tomasello 2010). Language is central to social learning and cultural developments and inter-generational transmission of knowledge in humans. Language and culture allowing for complexity in human organizations to be characterized, unlike, in ant colonies not only in terms of their size and modularity but in the differentiation in activities, both individual and collective. Moffett and Garnier indicate that with tiny brains, each worker ant is able to accomplish, on average, around 20 behavioral acts, and through these acts division of labor between them emerges. In human organizations, the division of labor is not only between individuals, but between organizational units, and the varieties of human technologies and organizational innovations generate enormous complexity in organizations forms and their specific configurations. Hierarchical authority develops to coordinate human organizational complexity (Blau 1968). With the advent of writing in human societies, indirect communication is facilitated through writing, and bureaucracies emerge to coordinate large-scale state organizations.

Which brings us back to the potential for self-organizing versus hierarchy in human organizations. Given the importance of direct and indirect communication for human (and ant) coordination of collective action, changes in communication and information technologies allow for variations in the forms and degrees of hierarchy in organization. Chandler (1977) showed how fundamental transformation in communication and transportation networks in the nineteenth century allowed for the dominance of large, vertically integrated firms, where the "visible hand" of hierarchy substituted for the invisible hand on the market.

The rise of digital information and communication technologies appears to provide opportunities for decreased reliance on hierarchical controls and for increase in selforganization in humans. At an extreme, organizations like Wikipedia, are organized, in large part, through stygmeric communication, not unlike ant colonies. Individual contributors to Wikipedia leave written traces of their contribution and other individuals work on those traces to alter, and ostensibly improve the content of Wikipedia entries. Communication between contributors is indirect, mediated through the internet-the digital analogy of ant trails. Do note that although minimal, even in Wikipedia hierarchical organizational authority exists (Arazy et al. 2015). Not every participant has the same rights in Wikipedia, even if "middle management" is quite limited.

Overall, I enjoyed my visit to the ant colony in the "Organization Zoo." It highlighted the importance of direct and indirect forms of communication in organizational design, including both hierarchical and non-hierarchical forms. The lesson for human organizational design is not that hierarchy is no longer necessary but that organizational design cannot focus only or even primarily on hierarchical authority relationships, and communication structures, direct and indirect are also critical. Furthermore, in designing organizations, individuality (with the requisite diversity) and sociality, while unimportant in ant colonies, should not be forgotten.

\section{Maybe ants can teach us how to achieve adaptive control of complex systems}

The Organization Zoo series is supposed to highlight new, unusual, or rare species of organizations. However, ant colonies are hardly new; they have been around much longer than human beings. Neither are they unusual. Or rare. Even so, the ants and their colonies make a very welcome appearance in the Zoo series with Moffett and Garnier's article "Ant Colonies: Building Complex Organizations with Minuscule 
Brains and No Leaders." Organization designers can learn from the principles at play in structuring and running ant colonies. Thus, I probe if ants can teach organization designers how to achieve adaptive control of complex systems.

As Moffett and Garnier remind us, cross-talk between biology and the social sciences has produced analogies (e.g. division of labor, swarm intelligence) that are productive for both fields. However, the present commentary suggests it is useful to go beyond analogy. At a sufficiently high level of abstraction, the processes and principles at play in ant colonies are not merely analogues to those found in human organizations, they are identical.

Moffett and Garnier relate several such processes and principles: division of labor and specialization, experiential learning, search and innovation, resilience. Division of labor in human organizations is advantageous because workers who are assigned to specialized, narrow tasks increase their productivity. The underlying mechanism driving improvement is experiential learning. While ant colonies gain from dividing labor among their workers, their gains do not stem from an ant's experiential learning. Rather, gains in productivity are achieved through reinforcement learning at the colony level. Ants who encounter sites rich in food reinforce the trail leading to those riches by adding their pheromones, a process which accelerates recruitment of further ants to follow the very same trail. This is but one example of how ants constantly influence each other's actions. While some of the mechanisms and principles at play in ant colonies-such as exploration and exploitation-are the same as we find in human organizations, other aspects of ant-colony-life exhibit notable differences. One such difference is that, within ant colonies, integration of the divided labor generally appears smooth and unproblematic while, in human organizations, it is associated with significant collaboration and coordination problems. In human organizations, collaboration problems occur because: (1) goals are not necessarily aligned between owners and workers, (2) goal conflicts tend to increase when hierarchical layers are added, (3) people care about their identities, social status, power, and wealth. Ant colonies are different. They avoid collaboration problems because the goal of each individual ant is perfectly aligned with the goal of its colony-as Moffett \& Garnier tell us, ants are self-less beings who dedicate their entire life to the success of the whole. They have no basis for caring about their identities, status, and wealth. Since there are no hierarchical layers in ant colonies - they are flat organizations-any remaining goal conflict is removed. Of course, the big question is how the ant colony manages to coordinate production and integrate specialized contributions from its many members? In human organizations, coordination costs increase with the extent to which production is specialized. Ant colonies do not appear to suffer such problems even when they, in part, employ parallel operations.
As ants influence each other, their behaviors become locally correlated. Like traffic in streets and walkways, the number of ants following a trail is regulated by positive and negative feedback loops. This is a reinforcement learning problem where the ant colony gains from improving the balance between resources spent on exploitation of existing trails against the exploration of new trails. Moffett and Garnier describe how ants, through various fascinating procedures such as adding their pheromones to trails, correlate their behavior such that they jointly are able to address the opportunities and threats they are facing. Big ant colonies can host more than 200,000 members. As they explore opportunities for acquiring new food sources, some ants follow one trail, others another trail, and so on. This implies that behavior is correlated among a subset of ants, e.g. the ants exploring a particular trail. As Moffett and Garnier write: "[1]ocally, an ant and its immediate neighbors influence each other's actions constantly." In big ant colonies, there are many local neighborhoods. At any point in time, the ant colony can be portrayed as a hierarchy of correlations-from 2-way to $n$-way. Perhaps a hierarchy of correlations is not an intuitive concept. Thus, it may be useful to think of an array, such as a bookcase, where pairwise correlations are placed on shelf number two, three-way correlations that cannot be reduced to pairwise correlation are placed on shelf number three, and so on.

The idea to look at the way ant behavior is correlated within an ant colony is useful because it may allow us to grasp an aspect of complexity that can further advance our understanding of the remarkable accomplishments of ant colonies. While complexity is commonly associated with ant behavior, the approach I am invoking here has not been considered much (if at all) in ant research. The idea of a hierarchy of correlations-the "book-shelf" —is captured by a notion of complexity from information theory according to which a system is complex when some higher-order correlations in that system cannot be inferred from lower order ones. Generally, the higher the order of the correlations we find in a system, the more information is contained in that system. According to this approach, the complexity of an evolving entity - such as an ant colony — can be defined in terms of the amount of information that it can store. Thus, complexity and entropy are inversely related in this approach. The higher the complexity, the lower the entropy, and the more information is stored in that system. The hierarchy of correlations present in an ant colony implies that it is an orderly system (relatively low entropy), which contains a high amount of information relevant to addressing opportunities and threats in its task environment. Control of the system is facilitated through the overall hierarchy of correlations among the ants' behavior.

Considering that ants dynamically change the way they interact with each other, and thereby also change the 
hierarchy of correlations among the ants' behaviors, they effectively tune how much information they jointly store about their task environment. For example, a reduction in higher-order correlations will allow the ant colony to better adapt to new external challenges, albeit at the expense of reducing the colony's internal order. This idea, that the hierarchy of correlations of ant behavior effectively promotes adaptive control of large-scale advanced production processes in ant colonies is well worth exploring beyond our Organization Zoo. Of course, the dynamics that generate correlations among humans is complicated relative to ants because humans have large brains that allow them to care about their identities, social status, power, and wealth. It is, therefore, interesting to examine whether these human traits are obstacles that limit the potential of human organizations. This would be the case if they cause humans to limit their mutual interactions and thereby realize fewer higher-order correlations than do ants. Or, the other way around, in what way do human organizations comprise correlation structures that facilitate control of operations beyond the grasp of any organizational member? Perhaps this is what occurs in the lunch-room, at the coffee place and in other situations that stimulate linkages among people beyond the formal organizational chart. Thus, the study of ant colonies points to a new exciting perspective on the role of the off-chart linkages among people that characterize corporate culture. Do these linkages generate levels of complexity-in the form of a hierarchy of correlations - that allow adaptive control of complex operations?

\section{Ant organizations and business partners}

Under the headline of organizational Zoo, it could not be more appropriate than to include the natural world's most conspicuous example of organizational complexity. The ants, as presented by Moffett and Garnier, surely represent the natural avant-garde of organization. Among the noticeable features of hyper-social organisms are the coherent and resilient structure, synchronized behaviour, self-sacrifice, cooperation with and manipulations of other species. Human organization can gain much from drawing parallels and making comparisons to the entangled and complex ant societies. However, we will in the following also underline some limitations to the comparison together with some suggestions of how organizational sciences may learn from the integration of other species into the ant 'organization'. The ants lift other species' effectiveness and success through proximity and exchange of goods and services. Often the interacting species have drastically different life history without division of labour and without elaborate social structure, but high efficiency may render the ants a very attractive business partner. In other words, nature simply offers a peek into examples of organizational design where a very high number of individuals work cost effectively towards a common goal in the face of unstable scattered resources and a changing environment. As described by Moffett and Garnier such organization occurs without central coordination and global information. The main organizing principle consists of local interaction as paralleled and distributed processes.

\section{Genetic similarity and high relatedness}

One way of classifying the degree of social organization is by the extent to which the individuals in a population interacts and depend on conspecifics. Within such a framework, ants and some wasps and bees, exhibit an extreme degree of sociality, so-called eusociality. This type of sociality encompasses societies where only few individuals indulge in reproduction, and where the reproductive individual's sterile offspring cooperate on raising their sisters and brothers. Some of the eusocial organisms have prompted scholars to view their encapsulated societies as super-organisms. Just like our well-known Darwinian individual, the common goal of a colony or super-organism consists of survival and maximum proliferation (through fission, budding or new queen establishment). The special reproductive structure causes the individual ants to be highly related if not completely genetically identical. Without getting into details about the ants special haplodiploid genetic system of reproduction it suffices to say that very high relatedness between individuals reduces the evolutionary conflict of who gets to proliferate. Consequently, it does not really matter who survive and proliferate the genes they share, as long as the common genes are passed on to the subsequent generations.

The high genetic overlap in eusocial societies and the fact that workers are sterile, means that we are dealing with an inherent level of complete goal-sharing. A worker ant has no incentive to defect from cooperation. It cannot reproduce on its own and hence only proliferate its gene indirectly by helping to proliferate the genes of its mother, the queen in the colony. Thus, it makes no sense for the worker to work for another colony, as the queen is unrelated (besides it would immediately be killed). Such absence of conflict and even friction is hard to imagine for systems of human organization. This characteristic feature of the ant society warrants caution when drawing parallels to human organisation. Nevertheless, there might be a lesson learned by the evolutionary analysis of the ant organization. It seems that removing internal competition (i.e. evolutionary conflict) is an important prerequisite for the scale and complexity of ant organization. Looking at a hierarchical human organization from an incentive-focused perspective the fierce competition among individuals to climb the hierarchical ladder might sometimes be a suboptimal waste of energy. The self-interest of climbing individuals could easily be antagonistic to the 
goal and interest of the organization, and hence counterproductive and potentially very expensive. This costly hierarchical load might be an important reason for flat organizations to be more cost effective.

\section{Ants and their business partners-trade across the species boundaries}

Ants engage in a wealth of interactions with other species including mutualisms benefitting both species. Among the most notably are the leafcutter ants' symbiosis with their leaf digesting fungus, as explained by Moffett and Garniner as well as the ants' interactions with honeydew producing insects such as aphids. In the latter case, ants and aphids obtain features from their partner that they lack themselves. Aphids get access to mobility from ant partners and ants obtain access to sugar via aphids (Stadler and Dixon 2005). Aphids do not move easily as their stylet mouthparts drill deep into pant tissue to obtain the plant sap they feed on. On the other hand, due to their sedentary life style, they do not need high amounts of carbohydrates, which are plentiful in plant sap. Thus, they excrete excess sugar as honeydew. Ants, on the other hand, do not have mouthparts that can access plant sap, but they are highly mobile and aggressive toward most other insects. A two-way partnership is obvious here. The aphids supply ants with sugar rich honeydew that the ants collect directly form the aphids when excreted. In return, the ants defend their aphid partners against natural enemies, carry them to new plant parts, house them by building galleries around them, and lastly increase aphid hygiene by removing their waste product, the honeydew. For both parts, this is a low-cost investment as aphids invest only their waste (a double win) whereas ants provide their mobility fuelled by the honeydew obtained from the interaction. The relationship is sometimes opportunistic so that aphids can exist both with and without ant body guarding. In other cases, aphid species rely fully on ant protection.

The ants' ability to cooperate and to divide and specialize on tasks facilitate the effective defense of aphids. Due to their cooperative skills, ants can permanently guard their aphid colonies. Some ants collect and carry honeydew from the aphid colony to the ant colony whereas others stay and defend the aphids. Furthermore, anatomically specialist agents, the soldier caste, may carry out this latter task. Permanent guarding is not only to keep out natural enemies from the aphid colony. It is also to monopolize their aphid partners and protect them against being taken over by competing ant colonies (Blüthgen et al. 2004).

Ants, however, are not always faithful business partners. If the aphid service, sugar, is in excess supply, ants may choose to exploit their partners for other resources. The aphids has sampled the scarce amino acids in the plant sap and incorporated them as proteins into their body tissue.
This resource is accessible to the ants if they prey on their aphid partners. When sugar is in excess, it has been observed that ants shift from tending their aphids to eating them instead (Offenberg 2001). This may induce competition among aphid colonies. If ants have access to both low and high producing aphid colonies (in terms of volume or quality of honeydew), they can focus their services on the latter and initiate predation on the former (Sakata 1994; Tena et al. 2013). As a result, high producing aphid species may experience better protection and become selected for this trait (Stadler and Dixon 2005). The procedure for how to select among business partners might be an area of inspiration from the world of ants although the specific example above seems too brutal to be directly applicable for human organizations.

Ants and their trading partners show variable dependence on each other. An extreme case of mutual obligation is the above-mentioned leaf cutter ants' interaction with their fungal food symbiont. Here, the fungus partner is the sole food of the ants and the fungus no longer exist in a free-living form (Mueller et al. 2005). It only exists in association with leaf cutter ants that take care of all its needs by feeding the fungus with leaves, provide it with optimal environmental conditions by digging out aeriated underground chambers and by vectoring the fungus to new locations by providing migrating ant queens with fungal tissue.

When the relation between ants and aphids or ants and fungi becomes obligate and symbiotic it becomes less clear what belongs to the ant society and what is separate. It seems, as if there are parallels to an organization that gradually works more and more intimately with suppliers or other partners until they become completely integrated. Organizational scholars similarly observe that certain new forms of organizations are less well defined and it is hard to determine the boundaries.

The ant-fungus symbiosis is also an example where a third partner is included to protect the two-way partnership. The ants' food fungus is under severe competition with other fungi that would thrive equally well on the leaf pulp supplied by the ants. To maintain the fungus garden as a monoculture, the ants grow bacteria on their bodies. These bacteria produce a fungicide that kill parasitic fungi of other species than their food symbiont (Kaltenpoth 2009; Holmes et al. 2016). Again, it seems that bacteria have become an integrated part of the organization.

In these examples, aphids and fungi illustrates how an ant society can be an attractive and capable business partner and open opportunity for intimate interspecies interactions. Whether the interacting species exploit and tap into the ants' organization-based efficiency, or the ants manipulate and exploit other species to their own benefit depends on the point of view. 


\section{Perspectives}

We propose to view the eusocial insects, such as ants, as a source of inspiration in the organisational sciences. There are, however, limitations to the analogy between the ant organization and various human organisations, as important sources of conflict are removed beforehand. This means that important human matters, such as trust, motivation and degree of overlap of the shared goal, are less relevant when it comes to eusocial organisms such as ants. Fortunately, nature is rich in species where comparable challenges of conflict handling is relevant to human organization and corporate life. We propose to look at e.g. cooperating mammals, as here the temptation to act selfish is ubiquitous. Interestingly, a mammalian species, the naked mole rat, was discovered recently as a eusocial species (Foster and Ratnieks 2005). The mole rats centralize and monopolize reproduction to one single female and one single male, while the other (20-300) individuals are temporarily sterile and may even show division of labour by role casting into being (mostly) worker or (mostly) anti-predator soldiers (Bennett and Faulkes 2000). It may offer something to human organizations to look at how evolutionary trajectories have escaped population states characterised by antagonistic tension and counterproductive incentive structures.

We believe that the eusocial insects offer insights into the (organizational) power of distributed processes and selforganization with de-centralized interaction-feed-back loops. An important point about many self-organized processes and mechanisms of distributed knowledge is that they are probably very cheap in addition to being robust to damage due to redundancy. The pheromone trail example of self-organization mentioned above, nicely illustrates how an exceedingly simple rule applied by many small and simple agents can result in very high search efficiency. Quorum sensing is another example of a simple and efficient mechanism of distributed and flat decision-making. Especially the new emerging forms of human organization such as collaborative communities may find inspiration in some of the 'ant techniques' of decentralized simple protocols of interaction and simple localized network feedback structures (Puranam et al. 2014).

\section{Conclusions}

We are grateful to the scholars who have shared their thoughts on the potential utility of comparing ant societies to human institutions. All five essays could easily be mined at length for insights around the benefits of such matters as simple rules, nonhierarchical structuring, self-organization, stigmergy, specialization, and modularity (in terms of both the parceling of tasks into independent pieces and the ability of individuals to operate somewhat independently of each other). Because addressing the many fascinating points that came up in these essays is impractical in our allotted space, we will restrict ourselves to a general closing statement.

A skeptic might conclude that given our differences from other animals, it is unreasonable to think about "organizations," or use words like "agriculture" or "employment," in connection to ant practices, even metaphorically. Fortunately, the authors in this issue, in the spirit of the Organization Zoo series, have nonetheless chosen to take this step, we think for good reason. After all, to be linguistically useful, most concepts, and the terms we use to describe them, must apply to more than one narrow thing. Just as the road network that interlinked the Roman Empire didn't correspond exactly to the trail systems of ants, neither was it identical to the paved roads produced by Italians today, or those of the ancient Inca; likewise, the highways of one ant species won't match those of any other. Despite this, the similarities can be instructive-as can be the differences. Each of the comparisons that have been made between ants and different aspects of human sociality (e.g., a colony as an individual being, a nation, a farm, a road builder, and, in our essay, an organization) yields some points of considerable utility and other points of absolute futility. For sure ant organizations have their limits. Eisenhardt and Furr aptly recognize that "ant colonies may occasionally move their nests, but they only slowly update their rules and never transform into something else," as when Kodak changed from primarily making sheets of film to prioritizing the manufacture of hardware like printers and scanners.

Yet notwithstanding the more plastic behavioral choices open to humans, both fruitful and failed comparisons to ants can teach us something. Warglien and Sartoris, for example, conclude that for humans, stigmergy is a rare and invariably transitory phenomenon dependent on planning and standardization. Social insects can employ it in a more substantial, long-term manner, and any standardization they show, say in how ants lay down material to construct nest walls, has to be worked out not through carefully laid plans but over eons of natural selection.

Certainly, a key distinction between ants and humans is the level of conflict between individuals. Though ant colonies are not without internal friction (consider the example we gave of workers being attacked for laying eggs when normally only the queen has that privilege), a colony is typically unified, being a highly incestuous affair, the workers commonly representing the offspring of a single mother, the queen. Although nepotism exists in human organizations, the degree to which it is found in ants and certain other social insects is without parallel in humans. This is an outcome of the close kinship between colony mates (Bach \& Offenberg summarize the basic biology). Even so there are ant species with genetically variable colonies that still manage 
to show extraordinary levels of altruism between unrelated members (these being offspring of different queens living within the same colony: Moffett 2012). As several of the essayists noted, people therefore live with a heady combination of cooperation and conflict that presents us with greater challenges in collaborating and coordinating our efforts than anything seen among the ants. People are far less often willing to die for their country, let alone their employer, than an ant is. Here the superorganism idea, where the individuals identify absolutely with the collective much like cells in the body, presents a better metaphor for a colony than does a human institution.

Part of the problem we face in this regard is the multiplicity of human social identities, a subject Ocasio rightly faults us for not mentioning (it's a subject the senior author explores in Moffett 2019). In sharp contrast to the strippeddown existence of an ant, for humans the demands of the job compete with our attention to our families, sports clubs, schools, religious affiliations, nation and other groups. Many companies are themselves labyrinths which we are expected to advance through over the course of our careers, even if we retain the choice of switching to another company (whereas ants can switch jobs but never colonies, to which they are totally loyal). What particularly fascinates, however, is that all this complexity isn't essential to the human condition. Prior to agriculture, people focused most of this sense of "group self" (Ellemers 2012) on their immediate family, society, and little else. The emergence of corporations has further amplified the intricacy of our social lives manyfold.

Another issue we neglected to address in our opening essay was the interrelationships between ant colonies, which differ dramatically from the market relations of human organizations. It is here that ants face the most social friction. Human institutions exist as parts of a webwork with other corporations that aren't always in competition, but instead often depend on one another for various goods and services-hence one firm can farm out work to another. An ant colony, however, is self-contained, generating everything it needs with zero dependence on other colonies of its own species, which it invariably treats as threats. Each colony typically controls a single nest, or home base. Yet even in the few ants whose colonies occupy more than one nest, member ants move freely between these housing units (i.e., colonies show no sign of splitting their labor pool among entrenched "departments") and the space taken up by all the nests is a unified territory from which foreign colonies are expelled without the slightest prospect of developing economic ties. The strongest analogies among the ants to corporate associations are therefore not interdependencies between colonies, which don't occur, but rather between ant colonies and certain other species, a topic Bach and Offenberg address. Such reliances include, for example, the dependence of ants on certain aphids that they "milk" for honeydew, relationships that can be very similar to those between humans and such domesticated species as cattle. Not mentioned by Bach and Offenberg, but where ants especially outshine anything in humans, is their intimate ties to specialized plants that provide colonies with food and housing within their living structures in return for protection from herbivores (so-called "ant plants").

Lastly, Thorbjørn Knudsen reminds us that in order not to be limited to simple analogies of human organizations with ant colonies —or for that matter, with any complex systems-we need a common theoretical framework that will allow us to draw more powerful comparisons. Since the early 1980s, the powerful theory of self-organization formulated in the previous decades has helped explain how large-scale organizations can emerge from the locally correlated actions of numerous, often simple and near-identical individuals (Camazine et al. 2001; Garnier et al. 2007). More recently, ideas from network science and information theory have permitted a deeper understanding of how distributed information is integrated inside a group and of how the structure and activity patterns of the interaction network determine the success or failure of the collective (Daniels et al. 2016; Farine and Whitehead 2015).

In particular, distinguishing direct and indirect influence from simple correlation between behavioral activities is crucial. To give an example from the social insects, if ant $\mathrm{A}$ lays a pheromone trail that is followed by ants B and C, all three ants will have highly correlated motion, but only ant A will have had influence over the behavior of the other two ants; the inverse is not true. By understanding the extent to which knowing the behavior of $\mathrm{A}$ informs our knowledge of the behavior of B and C (and vice versa), we can use information-theoretic measures such as transfer and causation entropy to reconstruct the causality chains responsible for structuring and regulating the collective activities of animal and human groups in the absence of top-down control (see Pilkiewicz et al. (2020) for a recent review). The combination of these theories and tools is making it possible to formally compare complex systems across classes and scales, and to eventually draw new (and better?) organizational principles for human social systems.

Acknowledgements The description of the market strategy of the fire ant was adapted by MWM from Moffett (2010) with the permission of the University of California Press.

Authors' contributions MWM was responsible for the conception, drafting, and revising of the manuscript. SG contributed to several sections and to editing and revising the manuscript. All authors read and approved the final manuscript.

Funding SG supported by the DARPA Young Faculty Award under Grant D19AP00046.

Availability of data and materials Not applicable. 
Competing interests None.

\section{References}

Altman EJ, Nagle F, Tushman ML (2015) Innovating without information constraints: Organizations, communities, and innovation when information costs approach zero. The Oxford handbook of creativity, innovation, and entrepreneurship. Oxford University Press, New York, pp 353-379

Anderson C, Franks NR (2001) Teams in animal societies. Behav Ecol 12(5):534-540

Arazy O, Ortega F, Nov O, Yeo L, Balila A (2015) Functional roles and career paths in Wikipedia. In: Proceedings of the 18th ACM conference on computer supported cooperative work and social computing. pp 1092-1105

Atran S, Medin DL (2008) The native mind and the cultural construction of nature. Life and mind. MIT Press, Cambridge

Baldwin C, von Hippel E (2011) Modeling a paradigm shift: from producer innovation to user and open collaborative innovation. Organ Sci 22(6):1399-1417

Barney J (1986) Strategic factor markets: expectations, luck, and business strategy. Manage Sci 32(10):1231-1241

Baumann O, Siggelkow N (2013) Dealing with complexity: integrated vs. chunky search processes. Organ Sci 24(1):116-132

Bennett NC, Faulkes CG (2000) African mole-rats: Ecology and eusociality. Cambridge University Press, UK

Bingham CB, Eisenhardt KM (2011) Rational heuristics: the 'simple rules' that strategists learn from process experience. Strateg Manage J 32(13):1437-1464

Bingham CB, Eisenhardt KM, Furr NR (2007) What makes a process a capability? Heuristics, strategy and effective capture of opportunities. Strateg Entrepreneurship J 1(1):27-47

Blau PM (1968) The Hierarchy of Authority in Organizations. Am J Sociol 73:453-764

Blüthgen N, Stork NE, Fiedler K (2004) Bottom-up control and cooccurrence in complex communities: honeydew and nectar determine a rainforest ant mosaic. Oikos 106:344-358

Bonabeau E, Theraulaz G, Deneubourg J-L (1996) Mathematical model of self-organizing hierarchies in animal societies. Bull Math Biol 58:661-717

Bremner RP, Eisenhardt KM (2020) Organizing form, innovation and performance: Lessons from the nascent civilian drone industry. Stanford University, Under review

Burghardt GM (1997) Amending Tinbergen: A fifth aim for ethology. In: Mitchell RW, Thompson NS, Miles H (eds) Anthropomorphism, anecdotes and animals. State University of New York Press, Albany, pp 254-276

Burton RM, Håkonsson DD, Nickerson J, Puranam P, Workiewicz M, Zenger T (2017) GitHub: exploring the space between boss-less and hierarchical forms of organizing. J Organ Des 6(1):1-19

Calabi P, Traniello JFA (1989) Behavioral flexibility in age castes of the ant Pheidole dentata. Insect Behav 2(5):663-677

Camazine S, Deneubourg J-L, Franks NR, Sneyd J, Theraulaz G, Bonabeau E (2001) Self-organization in biological systems. Princeton University Press, Princeton

Cassill D (2003) Rules of supply and demand regulate recruitment to food in an ant society. Behav Ecol Sociobiol 54(5):441-450

Chandler A (1977) The visible hand: the managerial revolution in american business. Harvard University Press, Cambridge, MA

Charbonneau D, Sasaki T, Dornhaus A (2017) Who needs lazy workers: Inactive workers act as a 'reserve' labor force replacing active workers, but inactive workers aren't replaced when they are removed. PloS ONE. https://doi.org/10.1371/journ al.pone. 0184074

Coase R (1937) The nature of the firm. Economica 4:386-405

Couzin ID (2009) Collective cognition in animal groups. Trends Cogn Sci 13(1):36-43

Cronin AL (2015) Individual and group personalities characterize consensus decision-making in an ant. Ethology 121(7):1-11

Daniels BC, Ellison CJ, Krakauer DC, Flack JC (2016) Quantifying collectivity. Curr Opin Neurobiol 37:106-113

Davidow WH, Malone MS (1992) The virtual corporation: structuring and revitalizing the corporation for the 21 st century. Harper Collins, New York

Davis JP, Eisenhardt KM, Bingham CB (2009) Optimal structure, market dynamism, and the strategy of simple rules. Adm Sci Q 54(3):413-452

Demaitre E (2019) Attabotics brings vision of ant-like efficiency to supply chains. The Robot Report, 16 August. https://www. therobotreport.com/attabotics-brings-vision-ant-efficiency -supply-chains/

Deneubourg J-L, Pasteels JM, Verhaeghe JC (1983) Probabilistic behaviour in ants: a strategy of errors? J Theor Biol 105(2):259-271

Detrain C, Deneubourg J-L (2008) Collective decision-making and foraging patterns in ants and honeybees. Adv Insect Physiol $35: 123-173$

Dornhaus A, Franks NR (2008) Individual and collective cognition in ants and other insects. Myrmecol News 11:215-226

Dunbar RIM (2010) How many friends does one person need? Dunbar's number and other evolutionary quirks. Faber and Faber, London

Dussutour A, Simpson SJ (2009) Communal nutrition in ants. Curr Biol 19(9):740-744

Dussutour A, Fourcassié V, Helbing D, Deneubourg JL (2004) Optimal traffic organization in ants under crowded conditions. Nature 428(6978):70-73

Ellemers N (2012) The group self. Science 336:848-852

Elliott M (2006) Stigmergic collaboration: The evolution of group work. J Media Cult 9(2) https://www.journal.media-cultu re.org.au/0605/03-elliott.php

Faraj S, Bijan A (2012) The materiality of technology: an affordance perspective. In: Leonardi PM, Nardi BA, Kallinikos J (eds) Materiality and organizing: social interaction in a technological world. Oxford University Press, Oxford

Farine DR, Whitehead H (2015) Constructing, conducting and interpreting animal social network analysis. J Anim Ecol 84:1144-1163

Feinerman O, Traniello JF (2016) Social complexity, diet, and brain evolution: modeling the effects of colony size, worker size, brain size, and foraging behavior on colony fitness in ants. Behav Ecol Sociobiol 70(7):1063-1074

Fewell JH (2003) Social insect networks. Science 301(5641):1867-1870

Firestein S (2016) Failure: why science is so successful. Oxford University Press, New York

Foster KR, Ratnieks FLW (2005) A new eusocial vertebrate? Trends Ecol Evol 20(7):363-364

Franks NR, Dechaume-Moncharmont F-X, Hanmore E, Reynolds JK (2009) Speed versus accuracy in decision-making ants: expediting politics and policy implementation. Philos Trans R Soc Lond B Biol Sci 364:845-852

Furr N, Dyer J (2014) The innovator's method. Harvard Business Review Press, Watertown, MA

Galbraith JR (1973) Designing complex organizations. Addison-Wesley, Reading

Garnier S, Gautrais J, Theraulaz G (2007) The biological principles of swarm intelligence. Swarm Intell 1(1):3-31 
Godfrey RK, Gronenberg W (2019) Brain evolution in social insects: advocating for the comparative approach. J Comp Physiol A 205(1):13-32

Gordon DM (2010) Ant encounters: interaction networks and colony behavior. Princeton University Press, Princeton

Grassé P-P (1959) La reconstruction du nid et les coordinations interindividuelles chez Bellicositermes natalensis et Cubitermes $\mathrm{sp}$. La théorie de la stigmergie: essai d'interprétation du comportement des termites constructeurs. Insectes Soc 6(1):41-80

Halfaker A, Geiger RS, Morgan JT, Reidl J (2013) The rise and decline of an open collaboration system: how Wikipedia's reaction to popularity is causing its decline. Am Behav Sci 57(5):664-688

Heylighen F (2007) Why is open access development so successful? Stigmergic organization and the economics of information. In: Lutterbeck B, Bärwolff M, Gehring RA (eds) Open Source Jahrbuch. Lehmanns Media, Berlin

Hölldobler B (1999) Multimodal signals in ant communication. J Com Physiol A 184(2):129-141

Hölldobler B, Wilson EO (2008) The superorganism: The beauty, elegance, and strangeness of insect societies. WW Norton, New York

Hölldobler B, Wilson EO (2011) The leafcutter ants: civilization by instinct. WW Norton, New York

Holmes NA, Innocent TM, Heine D, Bassam MA, Worsley SF, Trottmann F, Patrick EH, Yu DW, Murrell JC, Schiøtt M, Wilkinson B (2016) Genome analysis of two Pseudonocardia phylotypes associated with Acromyrmex leafcutter ants reveals their biosynthetic potential. Front Microbiol 7:2073-2089

Jung J, Concannon C, Shroff R, Goel S, Goldstein DG (2017) Simple rules for complex decisions. SSRN 2919024

Kaltenpoth M (2009) Actinobacteria as mutualists: general healthcare for insects? Trends Microbiol 17:529-535

Lakhani KR, Lifshitz-Assaf H, Tushman ML (2013) Open innovation and organizational boundaries: Task decomposition, knowledge distribution and the locus of innovation. Handbook of economic organization: Integrating economic and organizational theory. Edward Elgar Publishing, Cheltenham, pp 355-382

Langridge EA, Franks NR, Sendova-Franks AB (2004) Improvement in collective performance with experience in ants. Behav Ecol Sociobiol 56(6):523-529

Latour B, Woolgar S (1979) Laboratory life. The construction of scientific facts. Princeton University Press, New York

Liebenberg L (2012) The art of tracking: the origin of science. New Africa Books, Cape Town

Marsden J (2015) Developing a Framework for Stigmergic Human Collaboration with Technology Tools: Cases in Emergency Response. Syracuse Univ., Ph.D. dissertation

McDonald RM, Eisenhardt KM. (2020) Parallel play: Startups, nascent markets, and effective business-model design. Admin Sci Q Forthcoming

McGlynn TP, Owen JP (2002) Food supplementation alters caste allocation in a natural population of Pheidole flavens, a dimorphic leaf-litter dwelling ant. Insectes Soc 49(1):8-14

Moffett MW (1988) Foraging dynamics in the group-hunting ant, Pheidologeton diversus. J Insect Behav 1(3):309-331

Moffett MW (2010) Adventures among ants: a global safari with a cast of trillions. University of California Press, Berkeley

Moffett MW (2011) Ants and the art of war. Sci Am 305(12):84-89

Moffett MW (2012) Supercolonies of billions in an invasive ant: What is a society? Behav Ecol 23(5):925-933

Moffett MW (2019) The human swarm: how our societies arise, thrive, and fall. Basic Books, New York

Moffett MW (2020) Apples and oranges, ants and humans: The misunderstood art of making comparisons. Skeptics 25(1):8-9

Morgan J (2014) The future of work. Wiley, Hoboken
Moussaid M, Garnier S, Theraulaz G, Helbing D (2009) Collective information processing and pattern formation in swarms, flocks, and crowds. Top Cogn Sci 1(3):469-497

Mueller UG, Gerardo NM, Aanen DK, Six DL, Schultz T (2005) The evolution of agriculture in insects. Annu Rev Ecol Evol Syst 36:563-595

Offenberg J (2001) Balancing between mutualism and exploitation: the symbiotic interaction between Lasius ants and aphids. Behav Ecol Sociobiol 49:304-310

O'Mahony S, Ferraro F (2007) The emergence of governance in an open source community. Acad Manag J 50(5):1079-1106

Oster GF, Wilson EO (1978) Caste and ecology in the social insects. Princeton University Press, Princeton

Ott TE, Eisenhardt KM (2020) Decision weaving: Forming novel, complex strategy in entrepreneurial settings. Strateg Manage J forthcoming

Passera L, Roncin E, Kaufmann B, Keller L (1996) Increased soldier production in ant colonies exposed to intraspecific competition. Nature 379(6566):630-631

Penrose E (1959) The theory of the growth of the firm ( $\left.3^{\text {rd }} 1995\right)$, 3rd edn. Oxford, Basil Blackwell

Pilkiewicz KR, Lemasson BH, Rowland MA, Hein A, Sun J, Berdahl A et al (2020) Decoding collective communications using information theory tools. J R Soc Interface 17:20190563. https://doi. org/10.1098/rsif.2019.0563

Polilov AA, Makarova AA, Kolesnikova UK (2019) Cognitive abilities with a tiny brain: neuronal structures and associative learning in the minute Nephanes titan. Arthropod Struct Dev 48:98-102

Puranam P (2018) The microstructure of organizations. Oxford University Press, Oxford

Puranam P, Håkonsson DD (2015) Valve's way J Organ Des 4(2):2-4

Puranam P, Alexy O, Reitzig M (2014) What's "New" About New Forms of Organizing? Acad Manage Rev 39:162-180

Putnam LL, Nicotera AM (2009) Building Theories of organization: the constitutive role of communication. Routledge, New York

Ratnieks FLW, Foster KR, Wenseleers T (2006) Conflict resolution in insect societies. Annu Rev Entomol 51:581-608

Rezgui A, Crowston K (2018) Stigmergic Coordination in Wikipedia. In: Proceedings of the 14th international symposium on open collaboration (OpenSym 2018). association for computing machinery, New York, NY, USA, Article 19:1-12 https://doi. org/10.1145/3233391.3233543

Robertson BJ (2007) Organization at the leading edge: Introducing Holacracy ${ }^{\mathrm{TM}}$. Integral Leadership Rev 7(3):1-13

Robson SK, Traniello JFA (1999) Key individuals and the organization of labor in ants. In: Detrain C, Deneubourg J-L, Pasteels JM (eds) Information processing in social insects. Birkhäuser Verlag, Basel, pp 239-259

Sakata H (1994) How an ant decides to prey on or to attend aphids. Res Popul Ecol 36:45-51

Seeley TD (2002) When is self-organization used in biological systems? Biol Bull 202(3):314-318

Seeley TD (2010) Honey bee democracy. Princeton University Press, Princeton NJ

Smith VL (1998) The two faces of Adam Smith. South Econ J 65(1):1-19

Sorensen AA, Busch TM, Vinson SB (1985) Control of food influx by temporal subcastes in the fire ant, Solenopsis invicta. Behav Ecol Sociobiol 17(3): 191-198

Stadler B, Dixon AFG (2005) Ecology and evolution of aphid-ant interactions. Annu Rev Ecol Evol Syst 36:345-372

Sull DN, Eisenhardt KM (2015) Simple rules: How to thrive in a complex world. Houghton Mifflin Harcourt, New York

Tena A, Hoddle CD, Hoddle MS (2013) Competition between honeydew producers in an ant-hemipteran interaction may enhance 
biological control of an invasive pest. Bull Entomol Res 103:714-723

Theraulaz G, Bonabeau E (1999) A brief history of stigmergy. Artif Life 5(2):97-116

Tomasello M (2010) Origins of human communication. MIT Press, Cambridge, MA

Topoff H (1990) Slave-making ants. Am Sci 78(6):520-528

Tushman MA, Nadler DA (1978) Information processing as an integrating concept in organizational design. Acad Manage Rev 3:613-624

Visscher PK (2007) Group decision making in nest-site selection among social insects. Annu Rev Entomol 52:255-275

Wenzel JW, Pickering J (1991) Cooperative foraging, productivity, and the central limit theorem. Proc Natl Acad Sci 88(1):36-38

Williamson O (1981) The economics of organization: the transaction cost approach. Amer J Sociol 87(3):548-577
Woolley AW, Chabris CF, Pentland A, Hashmi N, Malone TW (2010) Evidence for a collective intelligence factor in the performance of human groups. Science 330(6004):686-688

Wystrach A, Beugnon G (2009) Ants learn geometry and features. Curr Biol 19(1):61-66

Yu B, Yang ZZ, Yao B (2009) An improved ant colony optimization for vehicle routing problem. Eur J Oper Res 196(1):171-176

Publisher's Note Springer Nature remains neutral with regard to jurisdictional claims in published maps and institutional affiliations. 